\title{
PROCESSOS FIGURACIONAIS DA PROFISSIONALIZAÇÃO DE PROFESSORES DE CRIANÇAS DE MATO GROSSO DO SUL ${ }^{1}$
}

\author{
Larissa Wayhs Trein Montiel iD2 e Adriana Horta de Faria (D)3
}

\section{Resumo}

O objetivo deste artigo é caracterizar, a partir da trajetória profissional de professores que atuaram com crianças, os aspectos da profissionalização docente no Mato Grosso do Sul. Os procedimentos teórico-metodológicos têm base na proposta de Norbert Elias, em particular na sociologia figuracional e na sociologia dos processos. A metodologia para a coleta de dados foi a história oral temática, a partir da entrevista com quatro professores. O resultado da pesquisa indica que a formação de professores nas escolas do sul de Mato Grosso do Sul, no período entre 1962 a 2007, foi marcada por uma formação precária e em serviço, na maioria das vezes. Entretanto, o lugar da docência pode ser entendido, sob a ótica desses professores, diante de uma perspectiva histórica, como uma oportunidade de utilização de competências e capacidades prezadas pelo indivíduo, da emancipação, responsabilidade, realização, implicação e eficácia, de desenvolvimento de novas aprendizagens e na tomada de decisão. Nesse sentido, é importante dizer que os professores buscaram, ao longo de sua trajetória profissional, o aperfeiçoamento da profissionalização e com isso garantiram a manutenção de sua carreira profissional. As figurações que cada indivíduo vivenciava, as tensões e os ajustamentos foram necessários para estabelecer sua ocupação funcional, a qual foi exigida uma profissionalização na carreira docente, uma vez que o professor leigo foi entendido como aquele que não tem a habilitação estipulada pela lei para lecionar, e o professor com magistério aquele que precisava buscar a formação superior.

Palavras-chave: Formação de professores; Sociologia figuracional; Profissionalização docente.

\section{FIGURATIONAL PROCESSES OF THE PROFESSIONALIZATION OF CHILDREN'S TEACHERS IN MATO GROSSO DO SUL}

\section{Abstract}

The aim of this article is to characterize, from the professional trajectory of teachers who worked with children, aspects of teacher professionalization in

${ }^{1}$ Esse artigo é proveniente da dissertação intitulada "Trajetórias Docentes: Memórias de Professores Homens que Atuaram com Crianças no Interior de Mato Grosso do Sul (1962-2007)" (FARIA, 2018) e da tese "Da Assistência à Educação Infantil: a Transição do Atendimento à Infância no Município de Naviraí - MS (1995-2005)"(MONTIEL, 2019).

Trabalhos de pesquisas defendidas no programa de pós-graduação da Universidade Federal da Grande Dourados (UFGD) na linha de pesquisa História da Educação, Memória e Sociedade.

${ }^{2}$ Doutora em Educação pela Universidade Federal da Grande Dourados (UFGD). Professora Adjunta na Universidade Federal de Mato Grosso do Sul (UFMS) campus de Naviraí (CPNV).

${ }^{3}$ Doutoranda em Educação pela Universidade Federal da Grande Dourados (UFGD). Professora da Universidade Federal de Mato Grosso do Sul (UFMS) campus de Naviraí. Integrante do Grupo de Pesquisa Educação e Processo Civilizador. 
Mato Grosso do Sul. The theoretical-methodological procedures are based on the proposal of Norbert Elias, in particular on figurational sociology and in the sociology of processes. The methodology for data collection used was thematic oral history, based on the interview with four teachers who collaborated with the research. The research results the analyzed interviews indicate that the training of teachers in schools in the south of Mato Grosso do Sul, in the period between 1962 and 2007, was marked by a precarious and in-service training, in most cases. However, the place of teaching can be understood, from the perspective of these teachers, from a historical perspective, as an opportunity to use skills and abilities valued by the individual, of emancipation, responsibility, achievement, implication, and effectiveness, of development of new learning and involvement in decision making. In this sense, it is important to say that teachers have sought, throughout their professional trajectory, the improvement of professionalization and thus ensured the maintenance of their professional career. The figurations that each individual experienced, the tensions and adjustments were necessary to establish their functional occupation, which required a professionalization in the teaching career, since the being of a lay teacher was understood as one who does not have the qualification stipulated by law to teach, and/or a teacher with a teaching profession who needed to seek higher education.

Keywords: Teacher training; Figurational sociology; Teacher professionalization.

\section{Introdução}

Ainda vejo o mundo com os olhos de criança Que só quer brincar e não tanta responsa Mas a vida cobra sério e realmente não dá pra fugir Livre pra poder sorrir, sim Livre pra poder buscar o meu lugar ao sol (Lugar ao Sol- Charlie Brown Jr.)

Nesse texto apresentamos um trecho da letra da música "Lugar ao Sol", indicando que na vida as escolhas direcionam nossa trajetória e nossas escolhas cobram um preço, mesmo que não sejam planejadas. Diante disso, relatamos a trajetória de quatro docentes que atuaram na educação de crianças e nesse contexto, também possibilitaram lugares de formação docente e de construção de uma profissionalização. Compreendemos que ao se constituir uma profissão, são exigidos conhecimentos específicos aliados a habilidades adquiridas, ou seja, é imprescindível a inferência teórica e não apenas a prática para se aprender o ofício. Tais conhecimentos devem ser testados por instituições autorizadas, outorgando, assim, a autoridade para a execução da atividade (GEBARA, 2012).

A formação de um indivíduo pode ser entendida como um processo que o acompanha toda a vida, está envolvida em diferentes dimensões como, por exemplo: a relação com a família de origem, o currículo escolar, as etapas 
oficiais da formação, o espaço profissional, o prolongamento universitário, as origens culturais e as funções sociais. No caso de professores, esse é um processo contínuo de reflexão autônoma e contribui para o enriquecimento dos saberes, valores pessoais e conhecimentos teórico-práticos, que compreende a diversidade dos "formatos" de aprendizagem como desenvolvimento profissional (JOSSO, 2010; NÓVOA, 2000).

A proposta deste artigo é caracterizar, a partir da trajetória profissional de professores que atuaram com crianças aspectos, como se figuram, historicamente, os aspectos da profissão docente no Mato Grosso do Sul. Nesse sentido, nós nos apoiamos nos apontamentos de Norbert Elias quanto à necessidade de examinar o percurso feito para que as profissões fossem constituídas no interior das sociedades, considerando que elas só podem ser entendidas a partir do contexto social e histórico. A profissionalização de uma atividade ocorre quando há "[...] mudança de uma comunidade inteira que cria as condições para o surgimento de uma nova ocupação e determina o curso de seu desenvolvimento [...]" (ELIAS, 2006, p. 89).

Os procedimentos teórico-metodológicos tem base na proposta de Norbert Elias, em particular na sociologia figuracional e na sociologia dos processos, especificamente nas discussões do texto "Estudos sobre a Gênese da Profissão Naval" e do livro "Escritos e Ensaios - Estado, Processo, Opinião Pública" (ELIAS, 2006), os quais aprofundam a teoria dos processos sociais a partir da constituição formativa da profissão naval inglesa, a relação entre gentleman e tarpaulins ${ }^{1}$, a qual evidencia os conflitos e as diferenças entre os oficiais da marinha, pertencentes à corte inglesa, e os marinheiros de profissão que aprenderam o seu ofício na prática.

Diante disso, afirmamos que compreendemos os indivíduos em suas figurações, ou seja, as pessoas de determinados grupos em seus vínculos específicos e móveis, o que "[...] significa dizer que o ponto de partida de toda investigação sociológica é uma pluralidade de indivíduos, os quais, de um modo ou de outro, são interdependentes [...]" (ELIAS, 2001, p. 184), nas relações que estabelecem uns com os outros. Para tanto, os indivíduos existem em "[...] figurações e só podem ser entendidos dessa forma por meio das relações de interdependência entre os indivíduos que se agrupam em figurações específicas" (ELIAS, 2006, p. 26).

Nessa perspectiva, esse padrão pode ser aplicado a pequenos ou a grandes grupos, como, por exemplo, os professores de uma escola ou de indivíduos que compõem um país (ELIAS, 1993). O conceito elisiano de interdependência trata, portanto de:

\footnotetext{
${ }^{1}$ Tarpaulin [no original], lona alcatroada, era naquela época (séc. XVII e XVIII) o que se podia chamar de capa do marujo comum. Tinha vários usos. Podia ser empregada como cobertura durante a noite; podia proteger do sol e do vento ou servir como capa de chuva. Assim, o nome daquilo que usavam como vestimenta, tarpaulin, tornou-se alcunha dos marujos. Como se tratava de uma palavra grande e pouco prática para um apelido, ao longo do tempo tornou-se pura e simplesmente tar (ELIAS, 2006, p. 79).
} 
[...] planos e ações, impulsos emocionais e racionais de pessoas isoladas constantemente se entrelaçam de modo amistoso ou hostil. Esse tecido básico, resultante de muitos planos e ações isolados, pode dar origem a mudanças e modelos que nenhuma pessoa isolada planejou ou criou. Dessa interdependência de pessoas surge uma ordem sui-generis (sic), uma ordem mais irresistível e mais forte do que a vontade e a razão das pessoas isoladas que a compõem. É essa ordem de impulsos e anelos humanos entrelaçados, essa ordem social, que determina o curso da mudança histórica, e que subjaz ao processo civilizador (ELIAS, 1993, p. 194).

Por esse ângulo, o que constrói a sociedade é o conjunto de relações que se estabelece entre todos que a constitui. Essas relações estão em constante devir, isto é: elas se fazem e desfazem, se constroem, se destroem, e podem ou não ser reconstruídas ou rearticuladas. O indivíduo não se constitui sem a sociedade e a sociedade não se estabelece sem indivíduos, mas são as relações entre ambos que estabelecem, entre os singulares, infindáveis e em eterno processo (ELIAS, 1994). Assim, as relações de interdependência entre indivíduo e sociedade se constituem ao longo do processo social e histórico e formam redes de relações. As figurações não são fixas, como afirma Landini (2005, p. 06):

Estão em continuamente em fluxo, passando por mudanças de ordens diversas, algumas rápidas e efêmeras e outras mais lentas e profundas e os processos que ocorrem nessas figurações possuem dinâmicas próprias, dinâmicas nas quais razões individuais possuem um papel, mas não podem de forma alguma ser reduzidas a essas razões [...] o termo figuração pode ser definido como redes formadas por seres humanos interdependentes, como mudanças assimétricas em uma balança de poder, enfatizando o caráter processual e dinâmico das redes criadas por indivíduos.

O convívio dos seres humanos em sociedade tem sempre, segundo Elias (2006), mesmo no caos, na desintegração, na maior desordem social, uma forma absolutamente determinada. Sendo assim, é:

Incorreto tentar explicar eventos sociais simplesmente em função das ações humanas intencionais, os processos são engendrados pelo entrelaçar de ações intencionais e planos de muitas pessoas, mas nenhuma delas realmente os planejou ou desejou individualmente (LANDINI, 2005, p. 07).

Em outro aspecto, Elias (2006) enfatiza que todas as profissões, ocupações, ou qualquer que seja o nome que se atribua a um ofício, elas são peculiares, independentes, não depende de mas elas são contínuas nas diferentes épocas. Elas continuam existindo mesmo depois que esses seus representantes morrem. 
O pensamento de Elias (2006) demonstra que se pode reconstruir grandes processos históricos a partir de objetos aparentemente menores e sugere a possibilidade de observarmos as figurações sociais de grande escala por meio da análise das tensões que estruturam um micromundo social, e no caso de nossa pesquisa aplicada a-configuração ocupada na e pela docente. Significa dizer, que a constituição do indivíduo profissional da educação resulta das diferentes figurações em que estão imersas, nas redes de interdependência. Nessa perspectiva, as pessoas modelam suas ideias a partir de todas as experiências que tiveram no interior de sua configuração e estão vinculadas à formação sócio histórica e cultural do seu meio.

Nesse sentido, enfatizamos que compreendemos o processo de profissionalização de uma categoria professoral, constituída no sul do Mato Grosso do Sul, no período de 1962 a 2007, por meio de dois trabalhos de pesquisa: o primeiro, de mestrado e o segundo de doutorado, ambos vinculados ao Projeto de Pesquisa com financiamento da FUNDECT/MS intitulado "Trajetória Docente na Educação Infantil: Pesquisas em escolas públicas de Mato Grosso do Sul", realizados pelo Grupo de Estudos e Pesquisa "Educação e Processo Civilizador" (GPEPC), na Universidade Federal da Grande Dourados. As fontes possibilitaram verificar como os indivíduos estão imbricados em uma interdependência entre os indivíduos e a sociedade, ou seja:

Teia de acontecimentos individuais e sociais apontando que não procuramos na sociedade os fenômenos como coisas estáticas e não-mutáveis, mas, percebemos que a sociedade se constitui de relações entre indivíduos e, somos indivíduos que se aproximam e se distanciam conforme o jogo de interesses e necessidades, somos nós próprios um ser entre os outros (ELIAS, 1980, p. 13).

A necessidade de um comportamento regulado e autocontrolado é inerente aos grupos sociais. Nesse contexto, o que houve foi uma mudança profissional na ocupação de indivíduos que trabalhavam com crianças na trajetória profissional, o que nos permite inferir que ocorre o surgimento da necessidade de um novo profissional com formação específica, o que Elias (1980) chama de uma "sociologia dos conflitos" mediada por relações de poder entre grupos e/ou indivíduos imbricados em uma ambivalência de interesses.

\section{Trajetos da profissionalização docente no Brasil}

As Escolas Normais no Brasil são criadas ainda no período imperial e cumprem o papel, deste lugar específico, de formação para qualificar os professores devido a proposta de ampliação da escolaridade elementar. Essas escolas foram fundamentais para à formação do professor. Segundo Tanuri (2000), as primeiras instituições foram "[...] destinadas exclusivamente aos elementos do sexo masculino, simplesmente excluindo-se as mulheres [...]". Embora houvesse a necessidade de escolas de formação de professores, "[...] as poucas escolas normais do Brasil, pautadas nos moldes de medíocres escolas 
primárias, não foram além de ensaios rudimentares e mal sucedidos [...]" (TANURI, 2000 p. 65).

Posteriormente, em 1879, pelo Decreto n0.7.247, o Poder Central por meio da Reforma Leôncio de Carvalho (BRASIL, 1879), estabeleceu a necessidade da submissão dos alunos a exames de avaliação para a aprovação no curso das Escolas Normais. Foi um período em que se determinou o novo currículo, de certo modo ele estava pautado em determinações dos conceitos de gênero que fazia diferenciações das disciplinas para indivíduos que iriam cursar a depender do sexo. O currículo para as mulheres apresentava noções de economia doméstica e trabalho com agulhas para as mulheres. $E$, princípios de lavoura, horticultura e prática manual de ofícios para os homens. No final do império havia poucas escolas normais públicas, em algumas províncias às escolas eram separadas, uma para homens e outra para as mulheres (TANURI, 2000).

Algumas iniciativas contribuíram para desenvolvimento das escolas, entre elas Tanuri (2000) cita: "Almeida de Oliveira (18/9/1882), Rui Barbosa (12/9/1882) e Cunha Leitão (24/8/1886) esses projetos evidenciam que o papel das escolas normais no desenvolvimento quantitativo e qualitativo do ensino primário começava a ser reconhecido". Nesse contexto, aos poucos, as mulheres começaram a participar da formação docente e "[...] nos anos finais do império, as escolas normais foram sendo abertas às mulheres, nelas predominando progressivamente a frequência feminina [...]" (TANURI, 2000, p. 66). No entanto, o contexto indicava que:

De um lado, o magistério era a única profissão que conciliava as funções domésticas da mulher, tradicionalmente cultivadas, os preconceitos que bloqueavam a sua profissionalização, com o movimento a favor de sua ilustração, já iniciado nos anos 70 (século XIX). De outra parte, o magistério feminino apresentavase como solução para o problema de mão-de-obra para a escola primária, pouco procurada pelo elemento masculino em vista da reduzida remuneração. Em várias províncias, a destinação de órfãs institucionalizadas para o magistério visava ao seu encaminhamento profissional-como alternativa para o casamento ou para o serviço doméstico- bem como o preenchimento de cargos no ensino primário a custo de parcos salários (TANURI, 2000, p. 66-67).

Em finais do século XIX e início do século $X X$, com o apoio de pensadores e políticos, houve reforço no estereótipo da mulher como educadora nata. Isso devido ser considerada a atuação no magistério uma extensão das atividades que ela já exercia em casa. Nesse caso, poderia conciliar a vida doméstica com os afazeres da docência. No entanto, a possibilidade de avanço do trabalho feminino cresceu e na república, com a descentralização do suporte organizacional da educação aos estados e municípios, fica facultado a "instrução primária e a profissional inclusive o ensino normal" (TANURI, 2000, p. 68).

A partir deste período, o estado de São Paulo desenvolve um novo modelo de administração educacional, inspirados pelas filosofias cientificistas, que 
influenciaram os sistemas de outros estados, inclusive do Mato Grosso uno ${ }^{1}$. Diversas modalidades do curso normal foram implantadas e reformuladas, cujo objetivo esteve em pautar os ensinos nas bases científicas, contemplando questões teóricas e práticas (TANURI, 2000).

A escola normal, que originalmente foi destinada aos homens, teve no início do período republicano com a presença quase exclusivamente feminina. Esses docentes eram, também, os depositários de uma série de valores morais que a República exaltava, como: a honestidade, a laboriosidade e o patriotismo. Por volta de 1930, o movimento escolanovista questiona a estrutura do curso normal e propõe que as normalistas sejam preparadas para uma educação mais flexível, com a atenção voltada para o aluno.

Nessa perspectiva, de mudança educacional, a maioria das escolas normais passaram a ter escolas-modelos utilizando o método desenvolvido por Pestalozzi, denominado Pedagogia Intuitiva. Seu aspecto característico era oferecer, na medida do possível, dados sensíveis à percepção e observação dos alunos, para a implantação foram contratadas "professoras-diretoras de formação norte-americana [...]" (TANURI, 2000).

Em 1971, com a promulgação da Lei n. 05.692 (BRASIL, 1971), em plena vigência da ditadura militar, ocorreram reformas no âmbito da educação e a educação técnica passou a ser prioridade. A Escola Normal passa a ser chamada de Habilitação para o Magistério, tornando-se um curso de nível médio. Posteriormente, o mais recente reconhecimento de necessidade de formação adequada para a atuação docente está na Lei de Diretrizes e Bases da Educação Nacional - LDBEN 9394/96, a qual determina "[...] a formação de docentes para atuar na educação básica far-se-á em nível superior, em curso de licenciatura, de graduação plena, em universidades e institutos superiores de educação [...]" (BRASIL, 1996). Tal legislação, marca o fim da formação em escolas normais e magistério, passando para as instituições de nível superior, em alguns casos, ainda mantendo uma formação em nível médio para suprir demandas específicas de algumas regiões ${ }^{2}$.

De acordo com a concepção Elisiana, acerca da construção de uma profissão, é necessário observar que durante o processo de profissionalização docente houve divergências e disputas. Quanto ao verbete Professions, Elias inclui a necessidade de associações profissionais para o estabelecimento de

\footnotetext{
${ }^{1} \mathrm{O}$ estado de Mato Grosso (MT) era unificado pois o estado de Mato Grosso do Sul (MS) só foi criado posteriormente com a divisão ocorrida por meio da lei complementar $n^{\circ} 31$, de 11 de outubro de 1977, que desmembrou o antigo Mato Grosso (BRASIL, 1977). Optamos neste trabalho por usar a nomenclatura Mato Grosso uno, tendo em vista que a história dos professores começa antes da divisão do estado, mas também contribuirá com a história da educação de Mato Grosso do Sul.

${ }^{2}$ Houve ainda a institucionalização dos Institutos Superiores de Educação - ISE's e de seus cursos superiores a partir da promulgação da Lei de Diretrizes e Bases da Educação Nacional (Lei No 9394/1996) e as mudanças ocorridas na formação docente a partir da instauração das Diretrizes Curriculares Nacionais para o Curso de Pedagogia - DCNs-Pedagogia (Parecer CNE/CP N 5 de, 13 de dezembro de 2005 e instituídas pela Resolução CNE/CP № 1, de 15 de maio de 2006) 
regulamentações para o ingresso, regras de atuação e remuneração (ELIAS, 1964).

No Brasil, as Associações foram fundamentais ${ }^{1}$ na tentativa de articulação nacional dos (as) professores (as), pois eram reivindicados melhoria nas condições de trabalho e estruturação dos sistemas educacionais nos estados brasileiros (VICENTINI, LUGLI, 2009).

Diante desta circunstância, por volta da década de 1960, houve em São Paulo as primeiras mobilizações dos (as) professores (as) primários (as), eles (as) reivindicavam principalmente melhores salários e condições de trabalho, consequentemente o reconhecimento da categoria profissional.

Nesse contexto, quando embates ocorrem no interior das profissões há uma tentativa de firmar posições de poder nas novas configurações que se ajustam aos contextos sociais organizados. Para Elias, conflito é uma condição da civilização e nas profissões "[...] o conflito é uma das características básicas de uma instituição nascente [...]" (2006, p. 110) à medida que nos conflitos estão prescritos diversos interesses e distintos grupos.

Nessa luta por uma profissionalização uma de nossas entrevistadas relata como foi difícil o início de sua carreira após a conclusão do magistério na década de 1970, indica o motivo que levou sua saída da cidade de Presidente Bernardes, no estado de São Paulo, e sua vinda para o município de Naviraí, naquele momento, ainda Mato Grosso uno ${ }^{2}$. A professora Amélia de Andrade Pizatto veio buscar uma oportunidade de trabalho, em opção à zona rural do interior de São Paulo. Diz a professora:

Quando eu comecei, eu tinha feito a escola normal, eu fiz a escola normal e eu morava em Presidente Bernardes, no estado de São Paulo, e lá eu não tinha mais vaga. Estava lotado de professores, teria que ir para zona rural. Como eu já tinha meus irmãos que já moravam aqui e eram professores, eu estava com diploma da escola normal da época, vim para cá para dar aula. Não foi nem escolha, foi a opção que eu tive na época.

\footnotetext{
${ }^{1}$ Em Mato Grosso uno podemos citar a AMPP- Associação Mato-grossense de Professores primários e SINTEP-MT - Sindicato dos Trabalhadores do Ensino Público de Mato Grosso, com criação em 1965 (VICENTINI, LUGLI, 2009).Ainda, Associação Campo-Grandense de Professores (ACP) (1952), a Associação de Professores de Aquidauana (APA) (1963), a Associação de Professores de Corumbá (APC), a Associação Pontaporanense de Professores (APP) (1970) e a Associação Douradense de Professores (ADP) (1978) (BIASOTTO; TETILA, 1991), também se registra a existência da Associação Três-lagoense de Professores teve seu início, aproximadamente, em 1975. E em, 1979 foi criada a FREPOSUL (Federação dos Professores de Mato Grosso do Sul), que atualmente denomina-se FETEMS (Federação dos Trabalhadores em Educação de Mato Grosso do Sul) (RODRÍGUEZ, 2014).

${ }^{2}$ A colonização desses locais ocorreu ainda quando o estado de Mato Grosso (MT) era unificado, pois o estado de Mato Grosso do Sul (MS) só foi criado posteriormente, com a divisão ocorrida por meio da Lei Federal Complementar $n^{\circ} 31$, de 11 de outubro de 1977, que desmembrou o antigo Mato Grosso (BRASIL, 1977). Optamos, neste trabalho, por usar a denominação de "Mato Grosso uno", tendo em vista que a história dos professores começa antes da divisão do estado. Entendemos, contudo, que, ao recuperar essas fontes e documentos, a presente pesquisa também contribuirá com a história da educação do Mato Grosso do Sul.
} 
Enquanto Amélia de Andrade Pizatto ocupava seu espaço na configuração docente, muitos professores buscavam reconhecimento político e social, como exemplo temos nos anos de $1980^{1}$ as profissionais do magistério, em São Paulo, que intensificaram as mobilizações, articulando-se aos movimentos populares na luta pelo reconhecimento político e social. As mulheres, maioria dos profissionais da educação, nesse processo, demonstraram o posicionamento social e político, em uma sociedade em permanente processo de civilização (VICENTINI; LUGLI, 2009).

Isto posto, podemos dizer que o processo civilizador como algo em continuidade esteve (está) permeado por aspectos de gênero, quando localiza lugares e espaços para homens e mulheres, inclusive na determinação da profissão. Nesse sentido, Elias com o conceito de figuração colabora para compreendermos o espaço ocupado por mulheres e homens. Desse modo, as inclinações pessoais levam os indivíduos a se unirem e a longo prazo transformarem as estruturas sociais. Durante o processo de feminização do magistério, as mulheres, que não podiam estudar, passam para uma figuração de maioria na docência e a apropriar-se de aspectos característicos da profissionalização de uma atividade. Assim, percebemos uma constante busca de equilíbrio no sistema educacional, o que configura relações na balança de poder entre os pares.

\section{A Formação de professores em Mato Grosso Uno}

É interessante notar que na província de Mato Grosso a primeira iniciativa de implantação da escola normal foi instituída pela Lei Provincial no 8 , de 5 de maio de 1837, sua instalação ocorreu em 1840 e foi desativada em 1844. A província fica por 30 anos sem instituições para a formação de professores até que em 3 de fevereiro de 1874, em Cuiabá, se inaugura o Curso Normal. Em 1876 passa a atender as mulheres e é oi substituído pelo Liceu de Línguas e Ciências, pela Lei no 536, de 3 de dezembro de 1879, e sucedido pelo Externato do Sexo Feminino para formação de mestras. Este último foi criado com a reforma de 1889 e anexado ao Curso de Preparatórios, contudo a formação de professores ainda era um aspecto deficiente (CASTANHA, 2007).

No período da República, diante dos ideais de uma "nova civilização" mais moderna, houve iniciativas na educação como a criação de Grupos Escolares para a formação de indivíduos que colocassem em prática os preceitos organizacionais. Porém, nos primeiros anos da nova organização política o "[...] sistema educacional de Mato Grosso uno era simplesmente caótico, caracterizado pela escassez de professores e pela precariedade de material e estrutura física" (BRAZIL, et al, 2015, p. 191).

Em 1908, o então Presidente do Estado, Coronel Pedro Celestino Corrêa da Costa, viabilizou duas iniciativas para a melhoria da educação: a criação das escolas primárias, nas cidades mais prósperas do estado e a escola normal da

${ }^{1}$ Em Mato Grosso do Sul citamos: Movimento dos professores de 1980 no governo de Marcelo Miranda Soares; em 1981, o movimento da ADP de Dourados; 1982 a primeira greve do professorado; O movimento que resultou no decreto no 3004/85 que dispôs as eleições para diretores da rede estadual pública (RODRIGUEZ, 2014). 
capital. A educação possuía características que acompanhavam o desenvolvimento da região, como, por exemplo, a influência do coronelismo, a qual decidia quem era contratado para ser professor, bem como a abertura e fechamento das escolas (RODRÍGUEZ; OLIVEIRA, 2008; BRAZIL, et al, 2015).

As professoras formadas em escola normal eram vistas como verdadeiras regeneradoras da pátria, pois pautavam a prática no que existia de mais moderno no processo pedagógico. De acordo com Rodríguez e Oliveira (2008, p. 4) "[...] no caso de Mato Grosso, apesar desse ambiente modernizante e 'progressista o Ensino Normal não encontrou um espaço para se expandir".

Enquanto no Brasil os pioneiros da Escola Nova buscavam introduzir novos padrões pedagógicos, em Mato Grosso uno ainda buscava a difusão do ensino primário e a formação dos professores. Por volta dos anos 30 do século $X X$ existiam dois cursos de ensino normal, um deles em Cuiabá e o outro em Campo Grande. Com a Era Vargas (1930-1945), o governador Júlio Müller (1937-1945) incorporou a Escola Normal Pedro Celestino ao Liceu Cuiabano, introduzindo apenas o curso para o magistério primário. Sua alegação era o número de normalistas necessárias para atender as escolas primárias de todo o estado (RODRÍGUEZ, OLIVEIRA, 2008).

A região sul do estado, a partir da construção da estrada de ferro (Corumbá - Campo Grande), em 1914 e a imigração de árabes, japoneses, espanhóis, portugueses e italianos, além da emigração nacional, começou a se urbanizar e com o aumento da população houve a necessidade da expansão escolar, e para atender a deficiência de professores campo-grandenses instalouse a Escola Normal de Campo Grande, em 21 de abril de 1930. No que se refere aos discente, "[...] a escola contava, em 1933, com 28 alunos [...], porém, concluíram o curso, em 1934, somente 11 alunas e, em 1938, 45 alunas, totalizando 56 formandas" (RODRÍGUEZ, OLIVEIRA, 2008, p. 6).

Em 1940 a escola normal de Campo Grande foi fechada. A partir disso, a escola normal experimentou um processo de reabilitação e expansão, principalmente no setor confessional, contudo, segundo Rodríguez e Oliveira (2008), em 1952 o então governador Fernando Corrêa da Costa reconheceu a falta de habilitação, principalmente para os professores das áreas rurais e as dificuldades em recrutar professores homens. Em 1948 a escola normal de Campo Grande foi reaberta e recebeu o nome de Escola Normal Joaquim Murtinho, seus cursos sofreram reformulações e se mantiveram até 1973. Havia, ainda, outras escolas normais nos centros urbanos maiores.

No entanto, a região Sul do estado vivia uma figuração específica, pois com a exploração da erva mate houve um avanço fundamental para o povoamento e desenvolvimento da região. Desde o fim da época imperial e adentrando o período da república Thomas Laranjeira era quem comandava a extração ervateira da região, a mão de obra era composta por migrantes oriundos principalmente do Rio Grande do Sul e pelos homens naturais da terra, os indígenas. A maioria dos trabalhadores viviam nas fazendas e as escolas estavam nos centros urbanos, a instrução escolar não fazia parte da vida dos 
filhos dos trabalhadores, pois as crianças também eram força de trabalho (BRAZIL, et al, 2015).

Como aponta Brazil (et al, 2015) no extremo sul do estado, no município de Caarapó, no início do século $X X$, as famílias de melhores posses enviavam seus filhos para estudar nas cidades natal de seus pais. A partir de 1920, para os filhos dos trabalhadores foram instaladas nas fazendas as escolas provisórias. As meninas raramente estudam e quando podiam aprendiam as prendas domésticas. Os professores eram homens ambulantes ou andarilhos, pessoas que se instalaram por poucos anos na região. Também se ocupavam de lecionar alguns voluntários, entre eles as mulheres migrantes e imigrantes, geralmente esposas dos fazendeiros ou de funcionários que tinham algum conhecimento de leitura, escrita e aritmética. Muitas crianças não participavam nem mesmo da educação rudimentar que era oferecida.

Concomitante ao fim do monopólio da extração ervateira, o governo de Getúlio Vargas lança um projeto político denominado "Marcha para o Oeste" (1938), o objetivo era proteger o território a partir do povoamento do interior. Entre as ações propostas estava a Colônia Agrícola Nacional de Dourados (CAND) que se efetivou por volta da segunda metade do século $X X$, nessa época 0 governo oferecia terras gratuitas para despertar o interesse dos colonos, segundo Oliveira:

Um dos atrativos fundamentais, como mecanismo para atrair colonos para o projeto colonizador no sul de Mato Grosso, foi a distribuição gratuita de terras a trabalhadores rurais sem-terra e reconhecidamente pobres. A proposta era atrativa para quem sonhava em adquirir um pedaço de chão como meio de trabalho e sustento da família. Entretanto, a propaganda foi intensificada através da campanha Marcha para Oeste, visando garantir o sucesso na ocupação dos espaços geográficos (OLIVEIRA, 1999, p. 132).

Outras iniciativas para colonização foram os Projetos Integrados de Colonização (PICs), segundo Cavalcanti (2015) essa modalidade de responsabilidade estadual foi implantada a partir dos anos 1970. O INCRA (Instituto Nacional de Colonização e Reforma Agrária) era o órgão responsável pela infraestrutura como a abertura das estradas, construção de escolas e postos de saúde, também selecionava as famílias que iriam ocupar as terras. Segundo o autor, entre denúncias de fraudes, mais de 1.000 famílias ocuparam as terras na parte da região de Iguatemi, as quais posteriormente deu origem aos municípios de Mundo Novo e Itaquiraí, no sul de Mato Grosso do Sul. Uma das providências do INCRA foi a construção das escolas rurais onde atuaram dois dos nossos professores entrevistados.

O município de Naviraí nasce de um empreendimento imobiliário de Ariosto da Riva, empresário de Vera Cruz, São Paulo, que institui a colonizadora "Vera Cruz de Mato Grosso Ltda.". O primeiro grupo de pioneiros colonos chegaram em barcaças, via Rio Paraná, subiram pelo seu afluente, o Rio Amambaí, fundando um pequeno vilarejo que inicialmente foi chamado de 
povoado de "Vera Cruz". As primeiras famílias colonas se instalaram onde hoje é o Rancho São Lucas, entretanto o local já era habitado por índios guaranis. A cidade de Naviraí passou a ser conhecida como a "Capital da Madeira", tendo e proliferado muitas serrarias na região.

O município de Naviraí está situado no estado de Mato Grosso do Sul, na Mesorregião do sudoeste de Mato Grosso do Sul e Microrregião de Iguatemi. Foi fundado em 16 de abril de 1952, pela Colonizadora Vera Cruz Ltda., empresa comercial constituída com 18 sócios, registrada na Junta Comercial do Estado de São Paulo, sob n 206.916, tendo como diretores: Ariosto da Riva, Batista Otoloni e Vicente Geraldo Scarabotolo ${ }^{1}$ e foi emancipado em 11 de novembro de 1963 do município de Caarapó.

Durante as décadas de quarenta e cinquenta do século $X X$, no extremo Sul do Estado de Mato Grosso, hoje no sul do Estado de Mato Grosso do Sul, ocorreu a colonização de várias áreas, fato este realizado por iniciativa dos governos Federal e Estadual, [...]. No entanto, encaminhamentos também dados por empresas colonizadoras de cunho particular, ou por iniciativa de investidores que buscavam, em especial, obter lucratividade com a compra e venda de lotes. Entre as empresas que atuaram na área em pauta destaca-se: SOMECO: Sociedade de Melhoramento e Colonização que se fixou no município de Ivinhema; Companhia Viação São Paulo- MT, que ocupou áreas no município de Batayporã e Bataguassu, a Companhia Moura Andrade de Antônio Joaquim Moura Andrade, abrangendo a área do município de Nova Andradina e a Colonizadora Vera Cruz Mato Grosso Limitada, ocupando terras em Naviraí (GONÇALVES, 2015, p. 41, grifo nosso)

Diante disso, o vilarejo cresceu e no final dos anos de 1950 e início de 1960 passou a ser denominado de Distrito da Paz do município de Caarapó. A emancipação política aconteceu em no ano de 1963, elevando-se a município, desmembrado de Caarapó. Dois anos depois da emancipação que levou Naviraí a se tornar município, toma posse o primeiro prefeito João Martins Cardoso. Posteriormente, no final da década de 1960, tem início as aulas das $5^{\circ}$ séries no Ginásio Estadual de Naviraí, atual Escola Estadual "Presidente Médici". No mesmo período chega a Naviraí um grupo de professores, dentre eles: Júlio Garcia Gagnin, Luiz Aparecido de Oliveira, Valdomiro Araújo de Souza, Gilberto Álvaro Pimpinatti, Sílvio Antonio Fernandes e Natalício Serpa.

Nesse período, também tem início a construção do Grupo Escolar Marechal Rondon, a princípio as instalações foram numa construção de madeira com 8 salas de aula e, foi criada a primeira Delegacia de Ensino de Naviraí.

Segundo Messias (2013) a escola Municipal de Ensino Fundamental Marechal Rondon, iniciou suas atividades com o nome de Escola Rural Mista de Finoto, situada aproximadamente a dez quilômetros de Naviraí, enquanto ainda

${ }^{1}$ Fonte: http://naviraidiario.com.br. Acesso em: 27 de mar. de 2018. 
era distrito de Caarapó, entretanto, dado o grande número de crianças em idade escolar a escola foi levada à categoria de Grupo Escolar as Escolas Reunidas, que funcionavam com salas de aulas isoladas, depois foi alterado para Grupo Escolar Marechal Rondon, com a localização na zona urbana de Naviraí. Assim, foi iniciada a construção da primeira escola de Naviraí, "Grupo Escolar Marechal Rondon" e, na década de 1970 foi denominada Escola Estadual de 10 Grau Marechal Rondon.

A escola Marechal Rondon foi a instituição em que a professora Amélia de Andrade Pizatto, uma das entrevistadas, inicia sua atividade como docente "Eu comecei no Marechal Rondon quando ele estava aqui no centro, só tinha o Marechal Rondon, aqui no centro, hoje é onde funciona o Fórum". É possível perceber que as histórias da região se cruzam com as histórias vivenciadas pelos professores.

\section{Lugares da docência no sul de Mato Grosso do Sul}

Optamos por trabalhar com a história oral, pois "[...] a história oral surge como possibilidade de trazer à tona e registrar o que há muito as pessoas sabiam, falavam, vivenciavam, por intermédio de suas histórias pessoais e das relações estabelecidas na sociedade" (SARAT, 1999, p. 57). Vale dizer, portanto, que os nossos entrevistados foram atuantes em seus grupos sociais em determinados períodos de atividade na profissão.

A história oral também é uma prática social geradora de mudanças que transformam tanto o conteúdo quanto a finalidade da história (THOMPSON, 1992). Para o autor, essa metodologia altera o enfoque da própria história e revela novos campos de investigação, podendo derrubar barreiras entre os sujeitos. Assim, como metodologia para elaboração de documentos, a história oral é um recurso moderno que possibilita estudos referentes à vida social dos indivíduos. Trata-se da história do tempo presente, sendo também conhecida por "história viva" (MEIHY, 1996, p. 13). O estudo do presente possibilita conhecer os movimentos sociais e os indivíduos que atuam no contexto em que o historiador se situa.

Para direcionar as falas dos professores aos aspectos da vida, voltados a suas atuações profissionais e usamos o viés da história oral, temática em que os detalhes da história pessoal do colaborador apenas interessam ao revelarem aspectos relativos à análise da temática central.

Os professores participantes da pesquisa foram: os senhores João Batista Venâncio, Luiz Pereira dos Santos e a senhora Amélia de Andrade Pizatto. Ao ouvir os relatos dos professores e a trajetória de sua formação docente, podemos identificar além da história da região que é possível perceber como se revelou o processo de sua formação profissional. Passamos, assim, a apresentar a trajetória de vida destes indivíduos indicando a profissionalização da carreira docente.

Os professores apresentam uma história coletiva, que é também singular e universal, pois, a história de um grupo social é percebida de forma única por 
seus integrantes, o que Ihes permite vivências singulares. Ao mesmo tempo, essa mesma trajetória individual possui elementos que se-assemelham entre os componentes desse grupo. Dessa forma, as vivências desses indivíduos compõem um contexto maior, constitui parte da história de uma região e da profissão docente.

Diante disso, podemos compreender que os professores iniciaram a sua atuação concomitantemente com a colonização da região. O professor Luiz Pereira dos Santos começou a atuar na docência em 1962 e se aposentou em 2002, atuou por 40 anos na profissão docente, a maior parte de sua trajetória profissional foi na cidade de Mundo Novo, localizada no extremo sul de Mato Grosso do Sul na fronteira com o Paraguai. Trabalhou em escolas rurais multisseriadas e na área urbana. Casado, pai de dois filhos, sendo uma filha professora formada em pedagogia.

O colaborador da pesquisa vem de uma família de migrantes desprovida financeiramente. Nascido em Santa Cruz do Monte no estado de Sergipe, Luiz, aos 3 anos, vem com os pais e 11 irmãos para o Paraná, em busca de melhores condições de trabalho e se instalam no município de Icaraíma. Ao falar da infância ele expressa com orgulho:

Aí que vem o chumbo! É assim.... eu sou filho de pobre, às vezes eu brinco: mais pobre que a minha família é impossível, bem pobre mesmo, bem humilde mesmo, e somos do Sertão do Paraná, por que aqui (Mundo Novo) era o sertão também e nós éramos do outro lado (do rio Paraná), quando nós chegamos tinha 4 casas em Icaraíma, estava formando a cidade ainda, nós viemos de Santa Cruz do Monte Castelo em Sergipe, eu tinha 3 anos de idade.

Luiz teve bom desempenho escolar e em três anos completou o primário. Seu professor, "que por incrível que pareça tinha o magistério", como diz Luiz, o observou e o convidou para atuar na docência. Assim, em 1971, na mesma escola onde estudou, Luiz iniciou a docência com crianças. Ele faz questão de contar:

Já era rapaz e o professor me observando. Ele falou para eu dar aula, porque os professores que davam aula tinham segunda série ou terceira série. Tinha uma professora, muito boa, ela só tinha o terceiro ano! Na época o professor que dava aula para mim no quarto ano, só tinha o segundo ano e era meu professor de quarto! Então essa professora começou a me observar e falava assim: olha nós vamos colocar esse moço para dar aula. Eu não conseguia brincar com as crianças porque já era adulto, eu ficava de pé encostado na parede. No outro ano eu fui dar aula para eles que eram meus colegas, foi muito bom!

O professor Luiz termina dois cursos, o técnico contábil e o magistério. No ensino superior o docente segue na direção da educação, cursando Pedagogia, na Faculdade de Filosofia, Ciências e Letras de Umuarama no Paraná 
e formado em 1982. Ele relata a respeito de sua escolha a influência da graduação na sua formação:

Já era uma coisa que estava dentro de mim! Eu não tenho muita diferença para te contar enquanto eu sou leigo e depois como professor habilitado. Não sei se talvez a vocação... na prática me esforçava muito, sempre trabalhei do mesmo jeito! Eu adorei estudar, fazer pedagogia, fazer faculdade! Para o meu trabalho o curso superior em pedagogia agregou o conhecimento, mas na verdade eu nunca senti que trabalhava errado! Nada disso, eu só aprimorei.

Já a professora Amélia de Andrade Pizatto chegou a Naviraí formada com o curso normal, durante sua trajetória profissional cursou Pedagogia e também pós-graduação em educação. Veio de Presidente Bernardes para trabalhar na cidade, pois no estado de São Paulo as vagas para professores eram somente na zona rural. Atuou em grande parte de sua carreira em turmas de primeiro ano, teve uma turma de segundo ano, mas preferiu voltar para o primeiro ano. A professora fala como começou sua carreira e os caminhos percorridos:

Eu comecei no Marechal Rondon onde hoje funciona o Fórum. Depois construíram o Juracy e eu passei para o Juracy mais próximo da minha casa. Eu já estava casada, o colégio novo, bonito, perto da minha casa. Eu fiquei vários anos. Depois mudamos para o Paraguai, divisa com o Brasil em Coronel Sapucaia. O lado do Paraguai é Capitão Bado. Levei minha transferência, eu já tinha meu primeiro filho fazendo o primeiro ano, levava meu filho para estudar na mesma escola e ficamos lá quatro anos. Sempre na primeira série, eu preferia. Depois fui para Amambai e meu marido ficou no Paraguai. Fui por causa das crianças, eu queria um estudo melhor. Fiquei um ano em Amambaí e voltei para Naviraí. Quando eu voltei para Naviraí eu não consegui a transferência e fui para a escola Vinícius de Moraes, que é do Varjão, uma realidade bem diferente, os alunos muito pobres, famílias pobres, não tinham estrutura nenhuma, uma realidade muito difícil que eu enfrentei.

A trajetória profissional de Amélia de Andrade Pizatto é repleta de mudanças: mudanças de escolas, mudanças de cidade, mudança de país, mas sempre com o foco na educação - trabalhando com as turmas de anos iniciais, tal experiência a credenciou para a coordenação da primeira creche em Naviraí. Após a sua aposentadoria atuou como professora contratada em licenças de outros professores e ainda mais um ano em uma turma de primeiro ano. No momento que surgiu a primeira creche no município, ela foi convidada, embora nunca tivesse trabalhado em creche, pode recomeçar sua carreira como coordenadora da instituição.

A história de vida do professor João Batista Venâncio é repleta de devoção religiosa. Casado pela terceira vez, ele tem 07 filhos entre os biológicos e os adotados. $O$ professor teve a sua primeira experiência na docência aos 12 anos 
e em Naviraí iniciou a carreira profissional no ano de 1963, aos 21 anos, encerrou suas atividades na escola em 2001, tendo percorrido 38 anos de atuação docente, desses mais de 20 anos em escolas rurais multisseriadas.

Venâncio Batista, de origem humilde, morou durante a infância com a família na cidade de Ribeirão Claro, no norte do Paraná. Seu pai trabalhava na serraria e ele era "coroinha no tempo que a missa ainda era em latim", segundo seu relato. Ele conta como a igreja esteve relacionada com a sua infância e a sua escolarização:

Naquele tempo tinha o seminário em Maringá onde a igreja me ajudou. Ajudou os meus pais que trabalhavam e, como assiduamente eu frequentava a igreja eles acharam que eu seria um bom elemento. Me perguntaram se eu queria ir para o seminário, eu disse que sim, conversaram com os meus pais e ele aceitou. Só que a gente trabalhava em serraria. Naquela época a gente comprava comida por saco, saco de arroz, de farinha, de açúcar e quando chegava 30 dias já praticamente não tinha mais. Inclusive meu pai pegou a colheita para a gente e a minha mãe colhia café do IBC (Instituto Brasileiro de Cafeicultores). E então fui (para o seminário), fiz estágio, meu comportamento era bom e eu fiquei estudando no colégio dos padres. Eu queria ser padre. Eu era empolgado pela beleza, os coroinhas, tudo aquilo, naquele tempo ia criança.

Aos 14 anos Venâncio foi transferido para Seminário Nossa Senhora da Glória, na comunidade de Santa Isabel/PR, na ocasião a escola primária da comunidade precisava de um professor de Ensino Religioso, então ele conta como se aproximou da docência:

Tinha aquela escola primária reconhecida pelo MEC e lá surgiu a minha vocação de professor, faltou professor de religião e o reitor perguntou quem gostaria de estar ali. Naquele tempo o ensino religioso era obrigatório nas escolas, hoje não é mais. E aí eu fui para sala e rezei com as crianças! Pedi ao espírito santo que iluminasse e, ele iluminou! Eu tinha 14 anos e a sala era quarto ano primário, eu trabalhava às quintas-feiras. Dali surgiu a vocação!

A família do professor Venâncio Batista, chega no ano de 1968 na Vila Fazenda Vaca Branca, no município de Naviraí. Logo a comunidade ficou sabendo que Venâncio "tinha estudo", e ele foi convidado a assumir como professor da Escola Rural na Fazenda Vaca Branca, o que conta lembrando do passado.

A gente apareceu lá na igreja e perguntaram pro meu pai: "o senhor tem alguma filha, algum rapaz lá estudado?" Meu pai falou: "eu tenho um filho que ia ser padre, estava no colégio de padre, e ele chegou do Rio Grande do Sul e está aqui com a gente". Vamos contratar ele para dar aula às crianças! Me chamaram o diretor José Paulino Júnior que foi candidato a prefeito aqui, junto com o 
Antônio Augusto dos Santos Virote, saudoso Virote. E assim eu entrei para lecionar para as crianças. Chegava crianças de todos os lugares, comecei através do ensino religioso e dos livros que eu tinha do primário. Comecei a dar aula em sala multisseriada - eu abracei a causa e pedindo sempre a Nossa Senhora para me iluminar e pedindo sempre a Jesus que as dificuldades que viessem eu conseguisse superar.

O professor Venâncio Batista acredita que sua entrada no magistério se deu por providência divina. Relata que "ser professor de crianças em primeiro lugar você tem que ter um dom eu fui levado pelas mãos de Deus". O que o professor chama de vocação pode-se entender como o que conduz, motiva, auxilia e orienta, é uma forma estereotipada de perceber o educador, essa concepção está atrelada a feminização do magistério que relaciona a maternidade a missão das mulheres ao educar crianças. Se por um lado esse entendimento contribui para o desprestígio da profissão, por outro lado, compreender a profissão de um ponto vista estritamente profissional pode incorrer em uma atuação mecanicista, não contemplando a subjetividade dos professores.

Venâncio já tinha cursado o 20 grau, mas não tinha o curso de Magistério. Os cursos oferecidos pela Secretaria de Educação e Cultura de Naviraí seguiam o mesmo sistema do INCRA, eram oferecidos em períodos de férias e não habilitavam para o magistério, somente promoviam capacitação. Ele estudou no projeto LOGOS II, que atendia especialmente a professores de $1^{\circ}$ a $4^{\circ}$ séries do 10 grau.

O professor Lídio, outro colaborador da pesquisa, lembra o que levou a cursar o LOGOS II. Segundo ele:

Lembra do Logos II? Corresponde ao segundo grau, era um curso pesado "você tem que se inscrever para tirar o segundo grau" e quem não queria? Quanto mais, ganhava mais um pouquinho e aumentava o salário. "É vamos fazer o segundo grau", consegui terminar Logos 2 em 78 ou 80 por aí.

O professor Venâncio também cursou o ensino superior em faculdade particular, primeiro tentou o vestibular para o Curso de Matemática que era oferecido pela Universidade Estadual de Mato Grosso do Sul (UEMS), mas não esperou ser convocado e foi estudar pedagogia na FINAV (Faculdades Integradas de Naviraí), na licenciatura o professor se formou no ano de 2000 e aposentou em 2002.

O professor Lídio Moía Caraíba, passou parte da infância no município de Caarapó, casado, pai de três filhas, trabalhou de 1975 a 2007, completando 32 anos de serviços prestados à educação das crianças, desses, mais de 20 anos em escolas rurais com salas multisseriadas no município de Japorã próximo de Itaquiraí, cidade em que reside e encerrou sua carreira.

Os pais do professor Lídio também foram migrantes, saíram do interior de São Paulo com a intenção de ir para o Paraná em busca de melhores condições (c) (1) 
de trabalho e sustento para seus seis filhos pequenos. Por motivos que ele não sabe explicar, acabaram chegando em Dourados em 1956, nesta época o menino estava com 6 anos e nunca tinha frequentado a escola.

Depois de alguns anos de dificuldades, seu pai foi trabalhar em fazendas com plantação de café e aos 10 anos Lídio era ajudante do pai na roça e da mãe nos cuidados com os irmãos menores. A família resolveu mudar para Caarapó, município localizado no extremo sul de Mato Grosso uno, e nas proximidades dessa nova fazenda havia uma escola. Surgia então, a oportunidade tão esperada pelo menino que tentava ler as cartilhas que o irmão mais velho, o que trouxe dos poucos anos que estudou em São Paulo.

Lá na outra fazenda de café falamos: "mãe, agora a gente precisa ir para escola", ela falou o seguinte: "vocês vão lá então". A gente ia lá e dava o nome, não precisava do pai. O nome da primeira professora acho que era Iracema, chegamos lá e olha... "eu queria estudar e a mãe mandou nós vim aqui dá o nome", "ah tá vou colocar o nome de vocês aqui, até o dia tal vocês podem vim... (responde a responsável pela matrícula)". E o material? Não tinha nada, não tinha nem uma folhinha de caderno... e para arrumar a borracha pegava pedacinhos de pneu e folha de caderno tinha que pedir para os outros. Depois que a gente começou a trabalhar na lavoura de café e conseguiu arrumar, o pai precisava comprar um caderno, tudo costurado à mão, a roupa que ia para escola era de saco, não tinha merenda escolar, nada, nada!

Ao completar 18 anos ele foi servir ao exército brasileiro em Iguatemi, ficou lá por 7 meses, quando retornou foi convidado pela Comissão Técnica de Projeto de Assentamento de Iguatemi a lecionar. Neste contexto, o professor Lídio ingressa na docência, "eu estava com 21 anos e com o ensino primário", mais um professor leigo em escola rural primária multisseriada. O professor Lídio completou o colegial por meio de cursos oferecidos pelo INCRA, e comenta sobre os cursos de capacitação que o órgão do Ministério da Agricultura oferecia:

Era curso em cima de curso que o INCRA promovia! Teve capacitação, aperfeiçoamento, inclusive o colegial. Nós fizemos o primeiro grau em poucos meses em um ano completei o ginásio, "arruma as malas que tem o curso de aperfeiçoamento em Ponta Porã ou Naviraí, Mundo Novo" era assim....

O professor Lídio cursou o ensino superior na APEC (Associação Prudentina de Educação e Cultura) em Umuarama no Paraná, segundo suas palavras, "fazendo a faculdade o salário aumentava, [...] vamos ganhar mais? Então vamos fazer o vestibular". Os professores Lídio, Luiz e Venâncio, ocuparam esses espaços no momento em que a figuração que participavam eram os mais escolarizados.

Ter escolarização, mesmo que não seja a habilitação para o magistério, que conferia mais poder na "balança" e pendia para o seu lado à medida que a maioria da população local não possuía tal formação. Portanto, esses indivíduos 
se constituíram professores de crianças em um período em que a profissão já era considerada feminina. Ao contrário da professora Amélia que vem para a região acreditando que para sua escolha profissional a possibilitaria passar por novas experiências, como já tinha a formação de magistério não tinha o desejo de se aventurar na docência da zona rural de São Paulo.

Desta maneira, a lembrança dos professores revela os trajetos percorridos sob a ótica de nossa escolha teórica, e assim procuramos analisá-las. A fim de compreender a história como um processo, Thompson (1981), assim como Elias e Scotson (2000), contribuem admitindo ser muito difícil teorizar ou formular a pesquisa sem a versão do campo empírico, visto que um processo histórico é indeterminado e permanece sujeito a certas pressões tanto teóricas quanto empíricas. Dessa maneira:

Em última análise, a lógica do processo só pode ser descrita em termos de análise histórica; nenhuma analogia derivada de qualquer outra área pode ter mais que um valor limitado, ilustrativo e metafórico [...] a "história" só pode ser teorizada em termos de suas propriedades peculiares (THOMPSON, 1981, p. 97).

Realizamos, assim, entrevistas que se apoiaram na memória destes indivíduos e em situações que emergiam do seu passado. Em vista disso, compreendemos a memória para além da capacidade humana de conservar e transmitir as produções materiais e intelectuais produzidas em diferentes tempos e espaços, a percebemos como a possibilidade de colocar em evidência indivíduos, vivências e trajetórias podem contribuir com seu grupo, dessa forma,

A memória permite a relação do corpo presente com o passado e, ao mesmo tempo, interfere no processo "atual" [...]. Pela memória, o passado vem à tona das águas presentes, misturando-se com as percepções imediatas, como também empurra, "desloca" estas últimas, ocupando espaço todo da consciência. A memória aparece como força subjetiva ao mesmo tempo profunda e ativa, latente e penetrante, oculta e invasora (MEIHY, 1994, p. 46-47).

Para tanto, pretendemos colaborar e estimular a reflexão que contribuam para a história da prática docente, visto que esses tiveram função fundamental na constituição da história local. Pois, trata-se de elemento essencial na articulação da história da educação e contribui no sentido de "[...] alicerçar-se numa reflexão na prática e sobre a prática, através das dinâmicas de investigação-ação e de investigação-formação, valorizando os saberes de que os professores são portadores e intimamente ligados com as práticas educativas" (NÓvOA, 1992, p. 64).

Desta forma, o que aparentemente parece natural, é resultado de um processo de longa duração, em que ocorrem transformações na sociedade, 0 que Elias chama de "processo civilizador" (ELIAS, 2011). Nesse sentido, as civilizações vêm indicando lugares, entendidos como figurações sociais para homens e mulheres, definindo a função de cada indivíduo na sociedade. Por 
figurações entendemos, à modo de Elias, como resultados das relações de interdependências recíprocas, ou seja, grupos de pessoas com vínculos específicos e móveis. Esse padrão pode ser aplicado a pequenos ou grandes grupos, como os professores de uma escola ou os indivíduos que compõem um país (ELIAS, 1993).

Esse processo regulatório de coerção e auto coerção acontece por ações planejadas e também não planejadas, o que Elias (2006) indica ser um processo cego e os indivíduos que vivenciaram a mudança regulatória provavelmente não tinham consciência de que sua vida pessoal e profissional poderia ser alterada. Como afirma Sarat (2011, p. 122):

As variáveis se dão em modelos que exprimem diferentes tipos de regulação do comportamento, nos tipos de coação externa e auto coação. Tais elementos existem em todos os grupos sociais e incidem num processo de individualização permitindo que o sujeito seja educado para ser parte do grupo a partir dos comportamentos internalizados, em um processo que passa de uma geração para outra.

Nesse encadeamento, é interessante perceber os movimentos profissionais do magistério imbricados com a história dos professores ao buscar melhores salários, condições de trabalho e capacitação. Nesse cenário, fica evidente como o movimento social e as ações dos indivíduos são relações de interdependência recíproca que os levou a buscar as melhorias das condições da formação. Partimos assim, de observar a trajetória dos profissionais da educação por meio de uma realidade aparentemente menor, dentro de um micro mundo social, e assim conseguimos perceber que os professores modelaram suas ideias a partir de todas as experiências que tiveram no interior de seu próprio grupo, diante de sua formação sócio-histórico e cultural vivenciada no seu meio.

\section{Considerações Finais}

As entrevistas analisadas indicam que a formação de professores, nas escolas do sul de Mato Grosso do Sul, no período entre 1962 a 2007, foi marcada por uma formação precária e em serviço, na maioria das vezes. Entretanto, o lugar da docência pode ser entendido sob a ótica desses professores diante de uma perspectiva histórica como uma oportunidade de utilização de competências e capacidades prezadas pelo indivíduo, da emancipação, responsabilidade, realização, implicação, eficácia, de desenvolvimento de novas aprendizagens e envolvimento na tomada de decisão.

Nesse sentido, é importante dizer que os professores buscaram ao longo de sua trajetória profissional uma melhoria da profissionalização e com isso garantiram uma melhoria e a manutenção de sua carreira profissional. Nas figurações que cada indivíduo vivenciava tensões e ajustamentos foram necessários para garantir sua ocupação funcional, a qual exigiu uma profissionalização na carreira docente, sendo assim, enquanto professor leigo ou professor com magistério precisavam buscar a formação superior. 
A história de vida dos professores se relaciona com a teoria elisiana, pois para se tornarem profissionais esses indivíduos, em suas redes de interdependência, buscaram aprimoramento de seus conhecimentos. Uma dessas bases compreende os conhecimentos científicos dentro da área de atuação. Outra engloba a experiência e prática da profissão e os instrumentos para que ocorra a construção do conhecimento. Na profissão docente, o professor, durante a sua formação acadêmica, dispõe de uma ampla gama de conhecimentos teóricos e práticos que o levam à construção de uma base para a atuação no seu campo de trabalho.

A concepção de que ao investir na formação gera uma situação profissional bem-sucedida e uma estabilidade financeira, foi um mecanismo para que estes indivíduos buscassem a formação superior. Porém, percebemos que eles estavam cientes que a devida preparação pode ser um fator determinante na melhoria da qualidade da educação, todos participaram de cursos de treinamento, habilitação para o magistério e a formação em nível superior. A formação de professores é baseada também em uma relação entre os saberes da vida, ou do cotidiano, em um processo contínuo de desenvolvimento pessoal e profissional. E entre ações planejadas por eles e ações não planejadas, indicando esse ser um processo cego, que foge do controle dos indivíduos.

\section{REFERÊNCIAS}

\section{BRASIL. Decreto n. 7.247 de 19 de abril de 1879 do Ministério do}

Império. Reforma o ensino primário e secundário no município da Corte e o superior em todo o Império. Império do Brasil de 1879 - Parte II Tomo XLII. Rio de Janeiro: Tipografia Nacional, p. 196-217, 1879. Disponível em http://www2.camara.leg.br/legin/fed/decret/1824-1899/decreto-7247-19abril-1879-547933-publicacaooriginal-62862-pe.html.

BRASIL. Diretrizes e Bases para a Educação Nacional. Lei 5692, de 11 de agosto de 1971. Diário Oficial da República Federativa do Brasil, Brasília, DF, 1971.

BRASIL. Diretrizes e Bases da Educação Nacional. Lei n. 9.394 de 20 de dezembro de 1996. MEC. Brasília MEC, 1996.

BRAZIL, Maria do. Carmo; MANCINI, Ana Paula; MONTEIRO, Juliana da Silva; TREVISAN, Macio Bogaz. A Escola republicana entre ervais e cafezais: cultura material no Sul de Mato Grosso (1908-1971). In. FURTADO, Alessandra Cristina; SÁ, Elizabeth Figueiredo de(Orgs). História da Educação do Centro- Oeste: instituições educativas e fronteiras. Cuiabá: EdUFMT, 2015. $236 \mathrm{p}$.

CASTANHA, André Paulo. O Ato Adicional e a instrução elementar no Império: descentralização ou centralização? fl. 558. Tese (Doutorado em 
Educação). Programa de Pós-Graduação em Educação - Universidade Federal de São Carlos. São Carlos-SP, 2007. (Tese de Doutorado).

CAVALCANTI, Tiago Leandro Vieira. Colonialismo, território e territorialidade: a luta pela terra dos Guarani e Kaiowa em Mato Grosso do Sul. fl. 470. Tese (Doutorado em História) - Programa de PósGraduação em História - Universidade Estadual Paulista, Assis-SP, 2013.

ELIAS, Norbert. "Professions". In: GOULD, Julius; KOLB, William. A dictionary of the social sciences. New York: Free Press.1964.

ELIAS, Norbert. A sociedade da corte: investigação sobre a sociologia da realeza e da aristocracia de corte. Rio de Janeiro: Jorge Zahar Editor, 2001.

ELIAS, Norbert. Estudos sobre a Gênese da Profissão Naval. NEIBURG, F. \& WAIZBORT, L. (org) Norbert Elias. Escritos e Ensaios. RJ. Zahar, 2006, p. 69-112.

ELIAS, Norbert. Introdução a sociologia. Lisboa: Edições 70, 1980.

ELIAS, Norbert. O processo civilizador: formação do Estado e civilização. v. 2. Rio de Janeiro: Zahar, 1993.

ELIAS, Norbert. 0 processo civilizador: uma história dos costumes. 2. ed. v. 1. Rio de Janeiro: Zahar, 2011.

GEBARA, Ademir. Figurações e Educação: A escola, os jovens e os professores. In: SARAT, Magda; SANTOS, Reinaldo dos. (Orgs.) Sobre Processos Civilizadores diálogos com Norbert Elias. $1^{\text {a }}$ ed. Dourados: Ed. UFGD, 2012. 330p.

GONÇALVES, Djalma. Lino. A colonizadora Vera Cruz Mato Grosso limitada e a formação de Naviraí. fl. 137. Dissertação (Mestrado em História). Programa de Pós-Graduação em História - Universidade Federal da Grande Dourados, UFGD, Dourados, 2015. Disponível em:

http://www.ppghufgd.com. Acesso em: abril de 2017.

JOSSO, Marie-Christine. Caminhar para si. Tradução Albino Pozzer, revisão Maria Helena Menna Barreto Abrahão. Porto Alegre: EDIPUCRS, 2010.

LANDINI, Tatiana. Savoia. A Sociologia processual de Norbert Elias. Anais... IX Simpósio Internacional Processo Civilizador. Ponta Grossa, Paraná, 2005. Disponível em: www.uel.br/grupoestudo/processoscivilizadores/portugues/sitesanais/.../art27.pdf Acesso em: maio de 2018. 
MEIHY, José Carlos Sebe Bom. (Re)Introduzindo a história oral no Brasil. In: MEIHY, José Carlos Sebe Bom (org.). (Re)Introduzindo a história oral no Brasil. São Paulo: Xamã, 1996. 342 p.

MESSIAS, Maria Lucia (Org.). Naviraí, 50 anos construindo sonhos. Naviraí - MS: Gráfica PSAF, 2013.

NÓVOA, António. (org.). Vidas de professores. 2a ed. Porto: Porto Editora, 2000.

NÓVOA, António. Formação de professores e profissão docente in NÓVOA, António. Os Professores e a sua formação. Lisboa: Instituto de Inovação Educacional, 1992, p. 15-34.

RODRIGUEZ, Margarita Victória. História dos Movimentos Sindical Docente de Mato Grosso do Sul: acordos salariais dos professores da rede estadual.

Anais... XII encontro da associação nacional de História. Seção Mato Grosso do Sul. 2014. Disponível em:

http://www.encontro.ms.anpuh.org/resources/anais/38/1411215199_ARQUIV O_ArtigoAnpuhconcluido.pdf. Acesso em 03 de ago 2017.

RODRIGUEZ, Margarita Victória; OLIVEIRA, Regina Tereza Cestari de. História da Escola Normal no Estado de Mato Grosso: implantação e consolidação no sul do estado. In: 162 ARAÚjO, José Carlos de Souza; FREITAS, Anamaria Gonçalves Bueno de; LOPES, Antônio de Pádua Carvalho (Org.). As escolas normais no Brasil: do império à república. Campinas: Alínea, 2008.

SARAT, Magda. Educação, memória e gênero: contribuições de Norbert Elias. InterMeio, Campo Grande, MS, v. 17, n. 33, p. 118-139, jan./jun. 2011. Disponível em: file://C:/Users/micro/Downloads/188-130-PB\%20(1).PDF. Acesso em: jan. 2018.

TANURI, Leonor Maria. História da Formação de Professores. Revista Brasileira de Educação. Campinas: n.14, p. 61-88, mai./jun./jul./ago, 2000.

THOMPSON, Edward Palmer. A miséria da teoria ou o planetário de erros: uma crítica ao pensamento de Althusser. Rio de Janeiro: Zahar, 1981.

VICENTINI, Paula Perin; LUGLI, Rosário Genta. História da Profissão Docente no Brasil: representações em disputa. São Paulo: Cortez Editora, 2009, 234 p. 


\section{FONTES ORAIS:}

Entrevista concedida a pesquisadora Larissa Wayhs Trein Montiel:

Amélia de Andrade Pizatto - julho/2017.

Entrevistas concedida a pesquisadora Adriana Horta de Faria:

Lídio Moía Caraíba- março/2017.

Luiz Pereira dos Santos - março/2017.

João Batista Venâncio - março/2017.

Recebido em: 26 de fevereiro de 2021.

Aceito em: 27 de junho de 2021. Publicado em: 30 de junho de 2021. 